\title{
THE EXISTENCE AND THE REPRESENTATIONS FOR THE GROUP INVERSE OF BLOCK MATRICES UNDER SOME CONDITIONS
}

\section{Wenjun ZHU AND Bin DENG}

Abstract. In this paper, we give the existence and the representations for the group inverse of block matrices $M=\left(\begin{array}{cc}M_{1} & A \\ B & D\end{array}\right)$ having a sub-block $M_{1}$ which is a combination of sub-block $A$ and $B$, and give the existence and the representations for the group inverse of block matrices $\left(\begin{array}{ll}A & B \\ C & D\end{array}\right)$ under some conditions. Finally, some numerical examples are given to illustrate our results.

Mathematics subject classification (2010): 15A09, 15A24.

Keywords and phrases: Block matrix, group inverse, range, null space.

\section{REFERENCES}

[1] J. J. Climent, M. Neumann And A. Sidi, A semi-iterative method for real spectrum singular linear systems with an arbitrary index, J. Comput. Appl. Math., 87 (1997), 21-38.

[2] S. L. CAmpbell and C. D. Meyer, Generalized Inverses of Linear Transformations, Dover, New York, 1991.

[3] A. Ben-IsRael And T. N. E. GReville, Generalized Inverses Theory and Applications, seconded, Spinger-Verlag, New York, 2003.

[4] S. L. CAMPBELL, The Drazin inverse and systems of second order linear differential equations, Linear Multilinear Algebra, 14 (1983), 195-198.

[5] C. D. MEYER, The role of the group generalized inverse in the theory of finite Markov chains, SIAM Rev., 17 (3) (1975), 443-464.

[6] C. BU AND K. Zhang, Representations of the Drazin inverse on solution of a class singular differential equations, Linear Multilinear Algebra, 59 (2011), 863-877.

[7] C. CAO, Y. GE AND Y. WANG, Group inverse for Two classes of block matrices over rings, Comput. Appl. Math., 33 (2014), 469-479.

[8] C. CAO, Some results of group inverses for partitioned matrices over skew fields, J. Natural Sci. Heilongjiang Univ, 18 (3) (2001), 5-7.

[9] C. CAO AND J. LI, A note on the group inverse of some block matrices over skew fields, Appl. Math. Comput., 217 (2011), 10271-10277.

[10] N. Castro-Gonzalez and E. Dopazo, Representation of the Drazin inverse of a class block matrices, Linear Algebra Appl, 400 (2005), 253-269.

[11] C. CAO AND X. TANG, Representations of the group inverse of some block matrices, Int. Math. Forum, 31 (2006), 1511-1517.

[12] K. P. S. BHASKARA RAO, The Theory of Generalized Inverses over Commutative Rings, Taylor and Francis, London and New York, 2002.

[13] Y. Wei And H. Diaob, Condition number for the Drazin inverse and the Drazin inverse solution of singular linear syatem with their condition numbers, J. Comput. Appl. Math., 182 (2005), 270-289.

[14] C. Bu, J. ZHAO AND J. ZhenG, Group inverse for a class block matrices over skew fields, Appl. Math. Comput., 204 (2008), 45-49.

[15] C. BU, M. LI, K. ZhANG AND L. Zheng, Group inverse for the block matrices with an invertible subblock, Appl. Math. Comput., 215 (2009), 132-139. 
[16] C. BU, K. ZHANG AND J. ZHAO, Some results on the group inverse of the block matrix with a subblock of linear combination or product combination of matrices over skew fields, Linear Multilinear Algebra, 58 (2010), 957-966.

[17] S. L. Campbell, C. D. Meyer, J. R. Rose and N. J. Rose, Applications of the Drazin inverse to linear systems of differential equations singular constant coefficients, SIAM J. Appl. Math., 31 (1976), $411-425$. 